\title{
The use of positive pressure devices by physiotherapists
}

\author{
L. Denehy*, S. Berney
}

\begin{abstract}
The use of positive pressure devices by physiotherapists. L. Denehy, S. Berney. (CERS Journals Ltd 2001.

ABSTRACT: The aim of this paper is to review the indications for use by physiotherapists, such as physiological rationale and the comparative efficacy of intermittent positive pressure breathing (IPPB) and continuous positive airway pressure (CPAP). A brief discussion of nasal intermittent positive airway pressure is also included.

The use of IPPB for post operative prophylaxis has not been supported in the literature. In patients with low lung volumes resulting from neuromuscular disease or spinal injury, IPPB may be useful in the acute phase to improve tidal volume and cough effectiveness.

The physiological benefits of CPAP to improve lung volumes are well documented in the literature. Physiotherapists use CPAP as an intermittent application in patients with low lung volumes following surgery. It is predominantly used as a second line intervention in the presence of refractory atelectasis and poor gas exchange. It may also be indicated in other patient groups with similar physiological problems.

Nasal intermittent positive airway pressure combines the beneficial effects of intermittent positive pressure breathing and continuous positive airway pressure. There have been many studies evaluating its effectiveness. These have been supportive for patients with neuromuscular disease and sleep disordered breathing, but more research is needed in patients with acute respiratory failure.
\end{abstract}

Eur Respir J 2001; 17: 821-829.

*School of Physiotherapy, The University of Melbourne, Melbourne, Australia. "Austin and Repatriation Medical Centre, Heidelberg, Victoria, Australia.

Correspondence: L. Denehy, School of Physiotherapy, The University of Melbourne, 200 Berkeley Street, 3052 Melbourne, Australia.

Keywords: Continuous positive airway pressure

intermittent positive pressure breathing physiotherapy

respiratory complications

Received: January 151999

Accepted after revision December 29 2000

The use of positive pressure devices has been part of physiotherapy management since intermittent positive pressure breathing (IPPB) was first used in clinical practice [1]. In some countries this part of patient management is performed by respiratory therapists rather than physiotherapists. In the 1990s there were many positive pressure devices from which to choose, depending on the health care setting in which the physiotherapist was working. These included IPPB, continuous positive airway pressure (CPAP), positive expiratory pressure (PEP) and nasal intermittent positive pressure ventilation (NIPPV). The aim of this paper is to review the physiological effects, equipment, indications and comparative efficacy relating to the use of IPPB and periodic (p) CPAP by physiotherapists. A limited discussion of nasal intermittent positive pressure ventilation (NIPPV) is included and the use of PEP was reviewed earlier in this series.

\section{Intermittent positive pressure breathing}

The clinical use of IPPB was first described by MotLEy et al. [2] in 1947 following its use during the second world war in aviation medicine. It may be used by physiotherapists in the management of spontaneously breathing patients and involves patient triggered delivery of positive airway pressure during inspiration [3]. The use of IPPB since this time has been both controversial and inconsistent [1].

\section{Physiological effects}

Whilst the comparative clinical benefits of IPPB over other methods of physiotherapy treatment has not been established, there is general agreement about its main physiological effects. IPPB has been shown to

Previous articles in this Series: No. 1. E. Houtmeyers, R. Gosselink, G. Gayan-Ramirez, M. Decramer. Regulation of mucociliary clearance in health and disease. Eur Respir J 1999; 13: 1177-1188. No. 2. C.P. van der Schans, D.S. Postma, G.H. Koeter, B.K. Rubin. Physiotherapy and bronchial mucus transport. Eur Respir J 1999; 13: 1477-1486. No. 3. E. Houtmeyers, R. Gosselink, G. Gayan-Ramirez, M. Decramer. Effects of drugs on mucus clearance. Eur Respir J 1999; 14: $452-467$. No. 4. L. Denehy. The use of manual hyperinflation in airway clearance. Eur Respir J 1999; 14: 958-965. No. 5. J.A. Pryor. Physiotherapy for airway clearance in adults. Eur Respir $J$ 1999; 14: 1418-1424. No. 6. B. Oberwaldner. Physiotherapy for airway clearance in paediatrics. Eur Respir J 2000; 15: 196-204. No. 7. E. Ernst. Breathing techniques - adjunctive treatment modalities for asthma? Eur Respir J 2000; 15: 969-972. 
increase tidal volume and therefore minute ventilation $[4,5]$. It does this by passively ventilating the patient [1] and as a result arterial blood gases are improved $[4,5]$. When IPPB is delivered to a relaxed patient, who is not fighting the ventilator, the work of breathing is reduced [4, 6]. EMMANUEL et al. [4] found that voluntary hyperventilation had a higher metabolic cost than the passive ventilation of IPPB. IPPB may also reduce the cardiac output as a result of raised intra thoracic pressure during delivery [7].

\section{Efficacy}

A large body of literature has been published examining the physiological effects of IPPB and its efficacy in different patient populations. Two patient groups were more extensively studied in the early literature. The efficacy of IPPB in the management of chronic obstructive pulmonary disease (COPD) was found to be mainly unsupported [8-10]. This may be due to the inappropriate choice of patient populations studied, the frequency of treatment application used and the confounding effects of concurrent chest physiotherapy techniques [1]. Beneficial effects of management in this patient group using NIPPV will be discussed later in this paper.

Investigation into the use of IPPB in the management of patients following surgery to prevent or treat postoperative respiratory complications has also been extensive [11-17]. The comparative efficacy of IPPB with incentive spirometry, deep breathing exercises, blow bottles, and "physiotherapy" has been studied. However, this literature is plagued by methodological problems. Control groups were not always used, descriptions of the techniques and dosage were often inadequate the frequency and application settings of the IPPB were also diverse. The outcomes of this literature are overwhelmingly equivocal, with IPPB conferring no added benefit to patients following abdominal or cardiac surgery when compared to the other above mentioned treatment modalities [11-17].

\section{Airway clearance}

IPPB is used in clinical practice, primarily to improve the lung volumes and to decrease the work of breathing. Few studies have investigated the effect of IPPB in clearing excess secretions from the lungs. PAVIA et al. [18] studied the effect of IPPB on mucus clearance by measuring radioaerosol clearance. They compared conventional physiotherapy, IPPB and combined treatment in eight patients with excessive secretion production and found no significant difference in tracheobronchial clearance between the three methods of treatment. Physiotherapy alone and the combined treatment showed a trend toward improved clearance, but with the small subject numbers, further conclusions were inappropriate. It is conceivable that in patients with excessive secretions, IPPB may need to be combined with gravity assisted drainage and chest wall vibrations for more effective cephalad movement of secretions. In their discussion PAviA et al. [18] argue that, on theoretical grounds, the use of IPPB alone may promote retrograde movement of secretions. It may be the combination of techniques that promote secretion clearance. Incorporating a slow inspiratory flow with IPPB may be important and chest wall vibrations during expiration may increase peak expiratory flow as well as intrathoracic airway narrowing [19]. The greater difference between inspiratory and expiratory airflow produced may favour two phase flow (gas liquid interaction) and enhanced tracheal mucus transport [20]. In this nonciliary dependent phasic flow, it is postulated that energy is transmitted from the moving air to the static liquid, shearing and moving the liquid in the direction of flow. It is thought that expiratory flow velocity needs to be higher than inspiratory for this type of clearance to occur [20].

In postoperative patients, IPPB may improve lung volumes and enhance the effectiveness of the cough. It is the initial attainment of high lung volume which allows maximum expiratory flow rates by increasing static lung elastic recoil and decreasing airway frictional resistance. The maximal cough promotes improved secretion clearance by the patient [21]. Physiotherapists use many techniques which may be effective in improving lung volumes and thereby cough after surgery; the skill is in deciding which treatment, if any, is necessary to obtain the best outcome for each individual surgical patient [22].

For patients who are very breathless and who have excess secretions, IPPB may reduce the work of breathing and rest the patient. The rest may allow them to produce a more effective cough to clear their secretions. IPPB can be delivered in gravity assisted drainage positions with the addition of chest wall vibrations on expiration [3]. However, these patients frequently do not tolerate any other physiotherapy intervention until breathlessness and fatigue recover. In patients with respiratory failure, IPPB may not adequately ventilate the patient and NIPPV may be more appropriate [23].

\section{Equipment}

A Bird or Bennett respirator is most commonly used for the delivery of IPPB by physiotherapists. These machines are powered by compressed gas, either air or oxygen. With the air mix control knob pulled out, the machine delivers a fraction of inspired oxygen $\left(F, \mathrm{O}_{2}\right)$ $\sim 0.4$ when run on oxygen. They have the facility for short-term humidification of the driving gas and are relatively easy to operate. Using a Bird respirator the operator selects the pressure and flow rate of the gas and the sensitivity of the system to patient triggering. Upon inspiration through the mouthpiece, a negative pressure is generated in the circuit and inspiratory flow proceeds until the preset pressure is reached, when flow ceases and the patient expires passively. The operator should adjust the machine settings until a maximal volume is delivered to the patient. A more detailed account of the equipment and method of application are given in WebBer and Pryor [3] and Bott et al. [1]. 


\section{Limitations of intermittent positive pressure breathing}

The following are a summary of the limitations: 1) Since IPPB is pressure cycled, the delivered tidal volume will vary with changing lung compliance [11]. This may result in noncompliant lungs receiving less volume [24]. Patient position must also be considered when establishing appropriate treatment settings since this will influence lung compliance and therefore lung volumes. 2) Compressed or bottled gas is necessary for delivery which means wall oxygen or air is needed. 3) Delivered $F \mathrm{I}, \mathrm{O}_{2}$ is limited to 0.4 or 1.0 . 4) Patients need to be cooperative and spontaneously breathing to trigger the machine using the mouthpiece. Occasionally a full face mask may be used for unconscious patients. However, full face masks are generally poorly tolerated by patients.

For these reasons IPPB has a limited place in the long-term or for more frequently applied patient treatments. Care must be taken if administering IPPB to a patient with a tracheostomy. Supervision of the patient during treatment is recommended.

\section{Indications for use}

The rationale for using IPPB should be based on its known physiological effects, the availability of other treatment modalities, the condition of the patient and the current research knowledge base.

Patients with low lung volumes or atelectasis in the postoperative period may not require a costly method of treatment such as IPPB [22]. The literature suggests that clinically relevant postoperative complications are in the order of $7-10 \%$ [25]. Previous studies indicate that other methods of postoperative prophylaxis such as ambulation and deep breathing exercises are equally effective [26] and less costly in terms of equipment and staff time. When complications develop and are refractory to conventional treatment, the application of CPAP or bilevel positive airway pressure may be the treatment of choice. If these devices are unavailable, IPPB may be useful, but should be used to deliver higher volumes of air at intervals of $1-2 \mathrm{~h}$. This requires high levels of operator skill in manipulating the settings appropriately [22]. It is possible that the shortcomings of previous research in this patient population may have been overcome, had the IPPB treatment regimen been more intensive [22].

Patients with reduced lung volumes and ineffective cough resulting from chest wall deformity, such as kyphoscoliosis, respiratory muscle weakness or prolonged immobility, may benefit from IPPB. Patients with respiratory muscle weakness resulting from spinal cord injury or neuromuscular disorders have a severe restrictive ventilatory defect characterized by reduction in forced vital capacity (FVC), forced expiratory volume in one second (FEV1) and peak expiratory flow rate [27]. This appears to contribute to loss of lung distensibility [28] and may lead to the development of life threatening respiratory disorders [29]. Intermittent positive pressure breathing has been reported to improve lung compliance in patients with kyphoscoliosis [30] but not in patients with respiratory muscle weakness resulting from spinal cord injury or neuromuscular disorders [29, 31].
Most of the previous research in this field has been performed in patients with established pathological conditions. Lung expansion with IPPB in acute quadriplegic patients has been shown to increase tidal volume and vital capacity during treatment, allowing improved lung inflation and ventilation. This may reduce the incidence of significant pulmonary complications and improve chest wall mechanics and pulmonary compliance in this acute patient group [32]. Periodic lung hyperinflation in the early stages of disease may alter the natural history of the condition [31]. However, patient numbers in this study were very small and more randomized clinical trials which assess the efficacy of IPPB in preventing lung complications in quadriplegic patients are needed [33]. Patients with respiratory muscle disorders, because they cannot periodically hyperinflate their lungs, would theoretically seem to be most obvious candidates for treatment with IPPB [34].

The use of IPPB has declined over the past $20 \mathrm{yrs}$. This is partly due to unfavourable research outcomes and partly a result of improving medical support and technology with the introduction of newer modes of positive pressure support. Despite this, IPPB may still have a role, albeit reduced, in the management of patients with reduced lung volumes. The use of IPPB to aid secretion clearance in the absence of low lung volumes and in postoperative prophylaxis is, in the opinion of the authors, questionable.

\section{Continuous positive airways pressure}

CPAP may be defined as the maintenance of positive airway pressure throughout the whole respiratory cycle [35]. Continuous positive airways pressure was first used in the treatment of acute pulmonary oedema in 1936 [36]. Its clinical use as a noninvasive technique was pioneered by GrEGORY et al. [37] in 1971 for newborn infants with respiratory distress syndrome. These authors introduced the term "continuous positive airways pressure". Its use was extended to adults with severe respiratory distress where CPAP was found to be effective in preventing intubation [38]. Most of the early use of CPAP remained in the intensive care setting.

The use of CPAP by physiotherapists involves intermittent or periodic application. Whilst the terminology seems contradictory, it is the intermittent application of the continuously applied pressure to the airways through inspiration and expiration that is under discussion. A discussion of the use of CPAP in weaning from mechanical ventilation, pulmonary oedema and obstructive sleep apnoea are beyond the scope of this paper.

\section{Physiological effects}

The effects of CPAP application on lung volumes are well documented in the literature. These include increased vital capacity [39], reduced respiratory rate [40], reduced minute ventilation [41] and increased functional residual capacity (FRC) [39, 40, 42, 43]. The 
increased FRC leads to a reduction in shunt, improved arterial saturation and lung compliance, and a decrease in the work of breathing [44-46].

The physiological mechanisms by which CPAP increases FRC are thought to be through a progressively increasing alveolar volume with increases in applied positive end expiratory pressure [47, 48], a time dependent increase in lung volume somewhat like pressure/volume hysteresis [47] and increased transpulmonary pressure at end expiration favouring recruitment of collapsed alveoli [49] possibly through collateral channels [50]. DugGin et al. [51] also postulate that its application may cause a release of prostaglandins into alveolar ducts which act to relax smooth muscle and increase lung volume.

Support for the presence of collateral ventilation (defined as the movement of air through pathways which bypass normal airways [52]) in the lungs is sometimes conflicting and is based predominantly on research of animal models or fixed cadaver lungs. On balance it is thought that collateral ventilation does exist in the human lung $[50,53,54]$. It is thought to increase with age [55] and with chronic lung disease [52]. The work of KIKUCHI et al. [56] found surfactant blocked collateral pores but postulated these opened in the presence of lung pathology. This work was supported by Morell et al. [57] in 1993 who found that in normal lungs, $80 \%$ of the collateral pores are filled with surfactant and that they are indeed very small, in the order of $2.6 \mu \mathrm{m}$. It has been suggested that different channels provide collateral ventilation at different states of lung inflation and that the bronchoalveolar channels of Martin are the most important in collateral ventilation [56].

Ventilation through collateral channels depends upon the resistance to flow and the driving pressure for flow [54]. The contribution of collateral flow to the distribution of ventilation depends on the magnitude of collateral flow resistance compared with airways resistance. As collateral flow resistance exceeds resistance through small airways, flow through collateral channels may be small when small airways are patent [55]. In the presence of obstructed alveoli, however, a pressure gradient favouring collateral flow may be created [54]. A high resistance to collateral flow has been demonstrated in normal lungs at FRC. However, as lung volume increases collateral flow, resistance decreases [55]. In addition, the driving pressure for collateral flow is thought to increase in vivo as a result of lung interdependence $[45,54]$. Consequently, in the presence of normal lung ventilation with no driving pressure from obstructed alveoli, collateral flow will not be favoured. It is postulated that in patients with atelectasis following surgery, application of CPAP may increase transpulmonary pressure, increase lung volume, reduce collateral flow resistance and promote collateral flow to obstructed lung regions [50].

\section{Efficacy}

It is well known that FRC decreases after surgery [58] altering the relationship with closing volume, which may lead to dependent small airways closure and arterial hypoxaemia [59]. Application of CPAP in the postoperative period following abdominal surgery has been shown to improve FRC when compared with other forms of prophylaxis [39, 43]. However, no benefits from CPAP were reported by CARLSSON [60] studying the same patient group. After open heart surgery CPAP has been reported to increase FRC but only during application with no carry over effect [61]. Others also report transient improvement in oxygenation in this patient group during CPAP application $[62,63]$. LINDNER [39] reported that FRC was improved when measured $15 \mathrm{~min}$ after application of CPAP in patients following abdominal surgery. There are no other reports which investigate the time course of the acute and carry over effects of intermittent CPAP following abdominal surgery. Influences on lung volume, of application and removal of positive endexpiratory pressure (PEEP) have been reported to follow a time course of $<1$ min [47] However, the carry over effects of PEEP and CPAP may be influenced by many contributing factors, including patient pathology and the existing relationship between their closing volume and FRC at the time of measurement.

There is support for a reduction in atelectasis with CPAP application after abdominal surgery $[42,43,46$, 64]. However, the incidence of significant postoperative pulmonary complications does not appear to be affected by type of prophylaxis in these comparative studies. It appears that CPAP is effective in improving lung volumes more quickly than voluntary inspiratory manoeuvres, but that this may not have important clinical ramifications [22]. There is controversy regarding which clinical outcomes are the most valid measures to use in assessing postoperative progress [22].

Application of CPAP has been successful in the management of acute respiratory failure (ARF) due to Pneumocystis carinii pneumonia [65], post-traumatic ARF [66, 67], pulmonary contusion and flail chest [68]. In these studies, CPAP was applied continuously and reversed hypoxaemia, preventing the need for intubation in $61 \%$ [67], 94\% [68], and 98\% [66] of patients. Others have documented successful outcomes for the use of CPAP in pulmonary oedema [69] and community acquired pneumonia [70].

Care is necessary in comparing these studies, however. The method of application of CPAP was extremely diverse. The level of positive pressure used varied 5-12 $\mathrm{cmH}_{2} \mathrm{O}$. GHERINI [71] found that the application of CPAP produced an increase in FRC proportional to the level of CPAP applied. The frequency, length of application time and number of days or hours of treatment also varied considerably between studies. Table 1 summarizes these differences in four comparative studies. In addition, the patient inclusion criteria, definition of successful outcomes and operational definitions of treatment techniques vary between studies.

An optimal treatment regimen has not been established for the use of CPAP by physiotherapists. Most studies examine the prophylactic use of CPAP postoperatively but not its efficacy in patients who have developed a significant postoperative complication; this research is still necessary. 
Table 1. - Summary of four comparative studies

\begin{tabular}{lccccc}
\hline Author & {$[$ Ref.] } & Application time & Frequency & $\begin{array}{c}\text { Duration of } \\
\text { postoperative treatment }\end{array}$ & $\begin{array}{c}\text { CPAP pressure } \\
\mathrm{cmH}_{2} \mathrm{O}\end{array}$ \\
\hline ANDERSEN & {$[42]$} & $25-35$ breaths & Hourly & $24 \mathrm{~h}$ & 15 \\
STOCK & {$[43]$} & 15 min & 2-hourly & 3 days & 7.5 \\
RICKSTEN & {$[72]$} & 30 breaths & hourly & 3 days & $10-15$ \\
LINDNER & {$[39]$} & 3 h continuously & daily & 5 days & 12 \\
\hline
\end{tabular}

There has been no research which measures sputum clearance as a primary outcome of treatment with CPAP. If atelectasis was associated with sputum plugging or sputum retention, it is conceivable that improving FRC and thereby collateral ventilation may allow airflow behind secretions and enhance their movement up the bronchial tree [42]. However, in suppurative lung disease, the physiological mechanisms whereby secretion clearance may be assisted by CPAP are less clear. Evidence exists supporting the efficacy of PEP in secretion clearance for this group of patients. The proposed mechanism for removal of secretions with PEP is improved collateral ventilation [73]. Despite this, CPAP may be utilized along with other techniques such as PEP, gravity assisted drainage and active cycle of breathing techniques in the management of patients with excess secretions. Further comparative studies measuring airway clearance outcomes using these treatment modalities are warranted.

\section{Indications for administration of continuous positive} airway pressure by physiotherapists

This will, to some extent, depend on the unit and team structures of different centres and the role of the physiotherapist within them. Factors similar to those discussed for IPPB also influence decision making when considering indications for treatment with CPAP. Indications are derived from the physiological benefits of CPAP [74]. These include conditions where there has been a significant fall in FRC and a significant deterioration in respiratory function and gas exchange as a result of atelectasis. The patient conditions may include: upper abdominal, thoracic, cardiac surgery, especially those patients at high risk of infection, who are not responding to voluntary lung expansion techniques such as mobilization and deep breathing; immobilized patients (especially those in a supine position); fractured ribs; uncooperative or confused patients who develop significant respiratory problems; and nocturnal ventilatory assistance.

\section{Precautions with continuous positive airway pressure treatment}

Since CPAP involves the application of positive pressure to the airways, there are potential risks associated with its administration. However, while there are few reports of adverse events in the literature, they relate to barotrauma [75] and loss of airway protection [76]. The use of CPAP in hypercapnia and/or hypoventilation may be inappropriate as tidal volume and minute ventilation are uncontrolled [74]. Precautions with CPAP treatment may include: facial fractures; lacerations; base of skull fractures; recent tracheal or oesophageal anastomosis; undrained pneumothorax; lung disease associated with air trapping or cyst formation; raised intracranial pressure; unstable cardiovascular system.

\section{Equipment}

There are many commercially available machines which can supply CPAP and it is also possible to put together a "home made" unit. The equipment features necessary to provide effective CPAP include: flow generator or gas source; high flow capability; reservoir system (depending on machine flow capabilities and patient inspiratory flow demand); manometer in circuit; valve or device to elevate end expiratory pressure, such as threshold resistors; face or nasal mask; and wide, smooth bore tubing.

High flow is necessary to adequately exceed the patients inspiratory flow demand and thus maintain a relatively constant positive pressure. A manometer is essential in order to set and monitor the CPAP pressure required and to reduce the possible risks of barotrauma with higher pressures. Fluctuations in pressure should be minimal [72], this should be checked and leaks or patient set up adjusted for optimal application of CPAP. Humidification can be provided during CPAP application. HARRISON et al. [77] suggested that two vapour humidifiers in series need to be added to provide effective humidification at high gas flows. There are no published clinical trials which compare outcomes of application of CPAP with and without humidification. Intermittent use of CPAP for a short time may not require humidification, but assessment of individual patient needs is essential.

The interface choices available are a nasal mask, full face mask or mouthpiece. Masks are held in position with soft elastic headgear, attached by velcro strips [78]. Many different sizes are available and masks should be transparent. The choice of interface depends on staff training, cost, patient preference and fit [78]. Masks need to fit so that an effective seal is obtained, air leaks around the mask are permissible provided the airway pressure is maintained [68]. PUTENSEN et al. [40] found no difference in efficacy of CPAP when a nasal and face mask were compared in 10 patients postextubation.

\section{Use by physiotherapists}

CPAP is commonly, but not uniformly, used by physiotherapists in Australia. There is currently no 


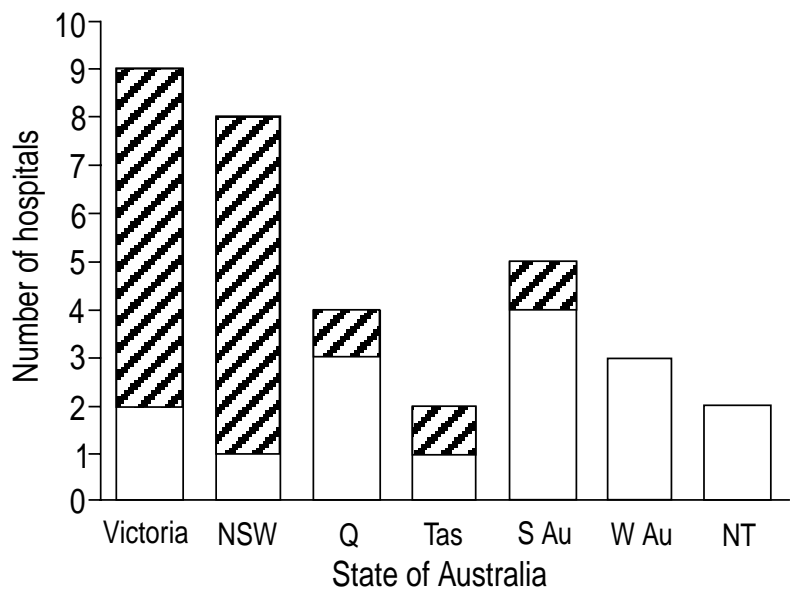

Fig. 1. - The patterns of use of continuous positive airway pressure (CPAP) in 32 Australian University teaching hospitals in 1996. (Z) represents the number of hospital physiotherapy departments using CPAP as a proportion of the total number of hospitals surveyed in each Australian State. NSW: New South Wales, Q: Queensland; S: South, W: Western, NT: Northern Territory; Au: Australia.

published data regarding its frequency of use in other countries. Physiotherapists generally use CPAP as an intermittently applied treatment, in contrast to its use in obstructive sleep apnoea, acute pulmonary oedema and weaning where it is a continuous application. In 1996 a telephone survey of thirty two University teaching hospitals in Australian capital cities was conducted to evaluate the patterns of use of CPAP by physiotherapists. The frequency of use of intermittent CPAP by physiotherapists, the types of patients treated, the referral structure and treatment regimens used were of particular interest.

Figure 1 illustrates that intermittent CPAP is used widely in hospitals on the east coast of Australia, and in fact in $53 \%$ of the Australian University teaching hospitals surveyed. Its use on the east coast may be

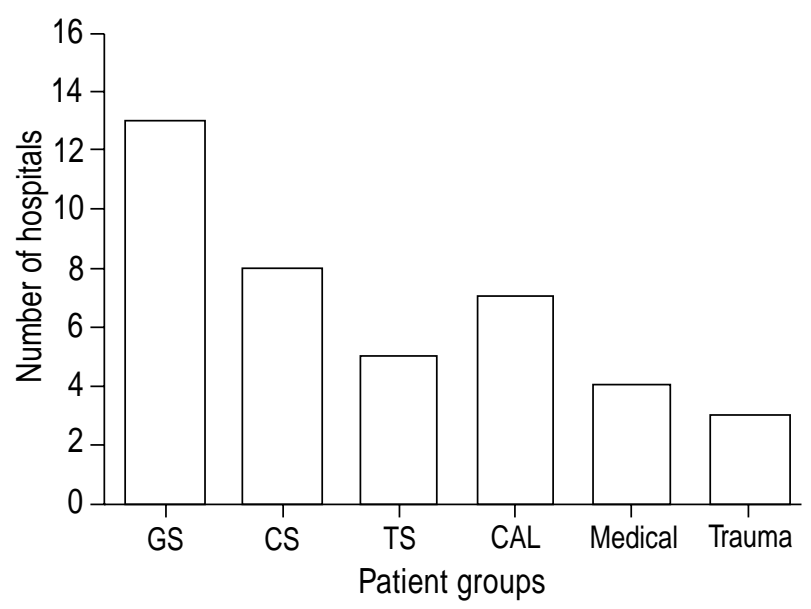

Fig. 2. - The patient groups receiving continuous positive airway pressure (CPAP) at the Australian hospitals surveyed. Some hospitals treat more than one patient group. GS: general surgery; CS: cardiac surgery; TS: thoracic surgery. CAL: chronic airflow limitation. influenced by the role of physiotherapists in the management of patients with neuromuscular disease and sleep disordered breathing, especially in New South Wales. When intermittent CPAP was used in management it was predominantly used as a second line treatment $(100 \%$ of respondents). It was most commonly used to treat deterioration in patients with low lung volumes following major surgery, once conventional treatment had failed. The patient conditions treated can be seen in figure 2. Physiotherapists could make decisions relating to introduction of CPAP treatment in $53 \%$ of the hospitals whilst it was solely a medical decision in $24 \%$ and a consultative decision by medical staff with physiotherapists in another $24 \%$ of hospitals using CPAP. The large variety of treatment regimens used reflected the diversity found in the current literature and result from a lack of research evidence upon which to base choices.

The prophylactic use of CPAP is not recommended. Results of studies following surgery have not shown that CPAP application affects clinical outcomes, but rather has acute effects on lung physiology [39, 43]. Further research into the efficacy of CPAP compared to conventional physiotherapy management in treating established postoperative complications is needed. In addition, establishing the optimal time to introduce CPAP into patient management, the level of positive pressure necessary and the optimal treatment frequency is essential.

\section{Nasal intermittent positive pressure ventilation}

NIPPV can be delivered to patients using either a volume preset or pressure preset model of ventilator [78]. The introduction of NIPPV to the management of patients was first described by ELLIS et al. [79] in 1987. Since that time the effectiveness and use of NIPPV has been extensively studied [80]. It is now considered a first line treatment for patients with neuromuscular and chest wall disorders requiring home ventilation [80]. Its use has expanded to treatment of chronic hypercapnic ventilatory failure resulting from neuromuscular disorders such as spinal cord injuries and muscular dystrophies, chest wall abnormalities, impaired ventilatory control and lung disease such as cystic fibrosis [80]. Use of NIPPV has been shown to improve blood gases, sleep quality [79] and exercise tolerance [81]. Studies examining its effect in acute respiratory failure and in weaning from mechanical ventilation have also been supportive. The reader is referred to extensive reviews of this literature by PIPER and WiLson [80] and SimONDs [82]. Use of NIPPV for deterioration following surgery is still to be evaluated. However, in Australia, when bilevel positive pressure devices are available, some centres use these to treat patients with refractory respiratory complications after surgery in place of CPAP or IPPB. Choice of bilevel positive airways pressure over CPAP may be influenced by the signs and symptoms of the postoperative patient. Bilevel devices which combine the beneficial effects of IPPB and CPAP may be more effective, but there is no comparative research to support this view. 
There is currently debate as to which profession is best able to administer NIPPV [23]. The physiotherapists knowledge of respiratory physiology and respiratory therapy equipment together with advanced patient handling skills means they are well placed to be part of the management team $[23,80]$. The physiotherapists role in management of this group of patients may be extensive and diverse. It may include choice of NIPPV equipment and settings, titration and implementation of ventilation, mask selection and fitting and skin care prophylaxis. The physiotherapist may also include education and advice about bronchial hygiene and exercise.

Research into the effectiveness of NIPPV has not focused primarily on airway clearance but in its role in the management of hypercapnic respiratory failure. For patients receiving NIPPV who have excess secretion production, treatment using gravity assistance and manual techniques may be employed. Prior to noninvasive ventilation, these patients may have been too breathless and fatigued to cough effectively or allow the effective use of these other airway clearance techniques [83].

\section{Discussion and recommendations from the literature}

The choice of which method of positive airway pressure to use in different clinical situations will be driven by the equipment and resources available, the knowledge and training of the physiotherapist and the referral structure in place. The use of IPPB has declined, due in part to the introduction of a more simple means of delivery of positive pressure. Compared with IPPB, the advantages of NIPPV are that it requires only electricity and room air, it has a choice of patient interface, the equipment is less cumbersome, varying levels of ventilatory support can be administered and more prolonged support is possible. One disadvantage of NIPPV was the difficulty in delivering high levels of oxygen to the patient. However, in newer equipment this is now possible. The physiological benefits of application are similar for both methods, that they can improve ventilation and gas exchange and decrease the work of breathing. In some patient populations this may "buy time" for other therapies. Bilevel devices for delivery of NIPPV combine the beneficial effects of IPPB and CPAP, and are flexible in that both inspiratory positive airway pressure (IPAP) and expiratory positive airway pressure (EPAP) can be delivered separately or together. Because of these advantages, the frequency of their use is increasing. Although intermittent CPAP has also been used to support patients in ventilatory failure, its most common physiotherapeutic role is in the treatment of low lung volumes and atelectasis which are refractory to more "conventional" physiotherapy treatments. It may be the treatment of choice to improve gas exchange in the presence of atelectasis due to the improvement in FRC, but may not be as effective as bilevel devices in the presence of hypoventilation. The haemodynamic consequences of application of any form of positive pressure must always be considered.

\section{General recommendations}

The following is a list of general recommendations: when using IPPB, treatment should be aimed at achieving large volume breaths; use positive pressure intervention (IPPB or NIPPV) as a first-line treatment in management of patients with acute spinal injury; the CPAP treatment regimen should include positive pressures $\geqslant 10 \mathrm{cmH}_{2} \mathrm{O}$, and application at short intervals such as $1-2 \mathrm{~h}^{-1}$ for $30 \mathrm{~min}$ if tolerated; introduce positive pressure support when signs and symptoms are refractory to voluntary lung expansion techniques.

\section{Conclusion}

The clinical evidence to support the use of these different positive pressure devices in some patient groups remains scant. Effective patient management lies not only in the technology available but in the clinical decision making skills of the physiotherapist. The physiotherapist should take into account the pathophysiological problems of the patient, the benefits and disadvantages of using the particular technique or equipment and the availability of resources. It is a matter of clinical judgement, together with a sound knowledge of physiology and current research in the area, which provides the best outcome for patients when considering which treatment technique is optimal. More scientific evidence from randomized, controlled trials comparing the efficacy of different techniques would significantly enhance this clinical decision making process.

\footnotetext{
Acknowledgements. The authors wish to thank D. Berlowitz for his helpful comments in editing this manuscript.
}

\section{References}

1. Bott $\mathrm{J}$, Keilty $\mathrm{S}$, Noone $\mathrm{L}$. Intermittent positive pressure breathing - A dying art? Physiotherapy 1992; 78: 656-660.

2. Motley H, Cournand A, Richards D. Observations of the clinical use of intermittent positive pressure. J Aviation Medicine 1947; 18: 417.

3. Physiotherapy skills: techniques and adjuncts. In: Webber BA, Pryor JA, ed. Physiotherapy for Respiratory and Cardiac Problems. London: Churchill Livingstone, 1993: 113-172.

4. Emmanuel G, Smith W, Briscoe W. The effect of intermittent positive pressure breathing and voluntary hyperventilation upon the distribution of ventilation and pulmonary blood flow to the lung in chronic obstructive pulmonary disease. J Clin Invest 1966; 45 : 1221-1223.

5. Torres G, Lyons H, Emerson P. The effects of intermittent positive pressure breathing on the interpulmonary distribution of inspired air. $A m \mathrm{~J} \mathrm{Med}$ 1960; 29: 946-954.

6. Sukumalchantra Y, Park S, Williams M. The effect of intermittent positive pressure breathing (IPPB) in 
acute ventilatory failure. Am Rev Respir Dis 1965; 92 : 885-893.

7. Pinksy M. Cardiovascular effects of ventiiatory support and withdrawal. Anaesth Analg 1994; 79: 567576.

8. Curtis JK, Liska P, Rasmussen HK, Cree EM. IPPB therapy in COPD. J Am Med Assoc 1968; 206: 10371040 .

9. Gormenzano J, Branthwaite MA. Pulmonary physiotherapy with assisted ventilation. Anaesthesia 1972; 27 : 250-257.

10. Thornton J, Darke C, Herbert P. Intermittent positive breathing in chronic respiratory disease. Anaesthesia 1974; 29: 44-49.

11. Ali J. Effect of post-operative intermittent positive pressure breathing on lung function. Chest 1984; 85 : 192-196.

12. Ayres S. Magnitude of use and costs of in-hospital respiratory therapy. Am Rev Respir Dis 1980; 122: 1113.

13. Baxter W, Levine R. An evaluation of intermittent positive pressure breathing in the prevention of postoperative pulmonary complications. Arch Surg 1969; 98: 795-798.

14. Celli B, Rodriguez K, Snider G. A controlled trial of intermittent positive pressure breathing, incentive spirometry, and deep breathing exercises in preventing pulmonary complications after abdominal surgery. Am Rev Respir Dis 1984; 130: 12-15.

15. Jung R, Wright J, Nusser R, Rossof L. Comparison of three methods of respiratory care following upper abdominal surgery. Chest 1980; 78: 31-25.

16. Iverson L, Ecker R, Fox H, May I. A comparative study of IPPB, the incentive spirometer, and blow bottles: the prevention of atelectasis following cardiac surgery. Ann Thor Surg 1978; 25: 197-199.

17. Oikkonen M, Karjalainen K, Kahara V, Kuosa R, Schavikin L. Comparison of incentive spirometry and intermittent positive pressure breathing after coronary artery bypass graft. Chest 1991; 99: 60-65.

18. Pavia D, Webber B, Agnew J, et al. The role of IPPB in bronchial toilet. Eur Respir J 1988; 1: 250S.

19. King M, Philips D, Chang H. Tracheal mucus clearance in high frequency oscillation. Am Rev Respir Dis 1984; 130: 703-706.

20. Wanner A. Does Chest physical therapy move airway secretions?. Am Rev Respir Dis 1983; 128: 701-702.

21. Irwin R, Rosen M, Braman S. Cough. Arch Int Med 1977; 137: 1186-1191.

22. O'Donohue W. Postoperative pulmonary complications. Postgrad Med 1992; 91: 167-175.

23. Bott J, Keilty S, Brown A, Ward E. Nasal intermittent positive pressure ventilation. Physiotherapy 1992; 78 : 93-96.

24. O'Donahue W. Maximum volume IPPB for the management of pulmonary atelectasis. Chest 1979; 76: 683-687.

25. Hall JC, Tarala RA, Tapper J, Hall JL. Prevention of respiratory complications after abdominal surgery: a randomised clinical trial. BMJ 1996; 312: 148-152.

26. Jenkins S, Soutar S, Loukota J, Johnson L, Moxhham J. A comparison of breathing exercises, incentive spirometry and mobilisation after coronary artery surgery. Physio The Practice 1990; 6: 117-126.

27. Ledsome J, Sharp J. Pulmonary function in acute spinal cord injury. Am Rev Respir Dis 1981; 124: 4144.
28. Estenne M, Gevenois P, Kinnear W, Soudon P, Heilporn A, De Troyer A. Lung volume restriction in patients with chronic respiratory muscle weakness: the role of microatelectasis. Thorax 1993; 48: 698-701.

29. McCool D, Mayewski R, Shayne D, Gibson C, Griggs $\mathrm{R}$, Hyde R. Intermittent positive pressure breathing in patients with respiratory muscle weakness. Chest 1986; 90: 546-551.

30. Sinha R, Bergofsky E. Prolonged alteration of lung mechanics in kyphoscoliosis by positive pressure hyperinflation. Am Rev Respir Dis 1972; 106: 47-57.

31. De Troyer A, Deisser P. The effects of intermittent positive pressure breathing on patients with respiratory muscle weakness. Am Rev Respir Dis 1981; 124: 132-137.

32. Stiller K. The effect of intermittent positive pressure breathing on lung volumes in acute quadriparesis. Paraplegia 1992; 30: 121-126.

33. Mansel J, Norman J. Respiratory complications and management of spinal cord injuries. Chest 1990; 97: 1446-1451.

34. Ingram R. Mechanical aids to lung expansion. Am Rev Respir Dis 980: 121-125.

35. Mechanical Ventilatory Support. In: Oh TE, ed. Intensive Care Manual. 3rd ed. Oxford, Butterworth Heinmann, 1990; 155-161.

36. Poulton E, Oxon D. Left sided heart failure with pulmonary oedema: Its treatment with the "pulmonary plus pressure machine". Lancet 1936; 231: 981-983.

37. Gregory G, Edmunds L, Kitterman J, Phibbs R, Tooley W. Continuous positive airway pressure and pulmonary and circulatory function after cardiac surgery in infants less than three months of age. Anaesthesiology 1975; 43: 426-431.

38. Greenbaum D, Millen J, Eross B, Snyder J, Grenvik A, Safar P. Continuous positive airway pressure without tracheal intubation in spontaneously breathing patients. Chest 1976; 69: 615-620.

39. Lindner K, Lotz P, Ahnefeld F. Continuous positive airway pressure effect on functional residual capacity, vital capacity and its subdivisions. Chest 1987; 92: 6670.

40. Putensen C, Hormann C, Baum M, Lingnau W. Comparison of mask and nasal continuous positive airway pressure after extubation and mechanical ventilation. Crit Care Med 1993; 21: 357-363.

41. Kesten S, Rebuck A. Ventilatory effects of nasal continous positive airway pressure. Eur Respir J 1990; 3: 498-501.

42. Andersen J, Olesen B, Eikhard B, Jansen E, Ovist J. Periodic continuous positive airway pressure, CPAP, by mask in the treatment of atelectasis. Eur $J$ Respir Dis 1980; 61: 20-25.

43. Stock M, Downs J, Gauer P, Alster J, Imrey P. Prevention of postoperative pulmonary complications with CPAP, incentive spirometry, and conservative therapy. Chest 1985; 87: 151-157.

44. Dehaven C, Hurst J, Branson R. Postextubation hypoxemia treated with a continuous positive airway pressure mask. Crit Care Med 1985; 13: 46- 48.

45. Applied Respiratory Physiology. 3rd Edn. London, Butterworths, 1987; p. 13.

46. Williamson D, Modell J. Intermittent continuous positive airway pressure by mask. Arch Surgery 1982; 117: 970-972.

47. Katz J, Ozanne G, Zinn S, Fairly B. Time course and mechanisms of lung volume increase with PEEP in 
acute pulmonary failure. Anesthesiology 1981; 54: 9 16.

48. Peruzzi W. The current status of PEEP. Respir Care 1996; 41: 273-279.

49. Lum H, Huang I, Mitzner W. Morphological evidence for alveolar recruitment during inflation at high transpulmonary pressure. Am Physiol Soc 1990; 90: 2280-2286.

50. Andersen J, Qvist J, Kann H. Recruiting collapsed lung through collateral channels with positive endexpiratory pressure. Scand J Respir Dis 1979; 60: 260 266.

51. Duggan C, Castle W, Berend N. Effects of continuous positive airway pressure breathing on lung volume and distensibility. J Appl Physiol 1990; 68: 1121-1126.

52. Terry P, Traystman R, Newball H, Batra G, Menkes H. Collateral ventilation in man. N Engl J Med 1978; 298: $10-15$.

53. Andersen J, Jespersen W. Demonstration of intersegmental respiratory bronchioles in normal human lungs. Eur J Respir Dis 1980; 61: 337-341.

54. Menkes H, Traystman J. Collateral ventilation. Am Rev Respir Dis 1977; 116: 287-309.

55. Terry P, Menkes H, Traystman R. Effects of maturation and aging on collateral ventilation in sheep. J Appl Physiol 1987; 62: 1022-1031.

56. Kikuchi R, Hildebrandt J, Sekizawa K, Sasaki H, Takishima T. Influence of lung volume history and increased surface forces on collateral resistance. Respiration Physiology 1992; 89: 15-25.

57. Morrell N, Roberts C, Biggs T, Seed W. Collateral ventilation and gas exchange during airway occlusion in the normal human lung. Am Rev Respir Dis 1993; 147: 535-539.

58. Bourn J, Jenkins S. Post-operative respiratory physiotherapy. Physiotherapy 1992; 78: 80-85.

59. Wilson R. Intermittent CPAP to prevent atelectasis in postoperative patients. Respiratory Care 1983; 28: 7173.

60. Carlsson C, Sonden B, Tyhlen U. Can continuous positive airways pressure prevent pulmonary complications after abdominal surgery? Intensive Care Med 1981; 7: 225-229.

61. Stock C, Downs J, Corkran L. Pulmonary function before and after prolonged continuous positive airway pressure by mask. Crit Care Med 1984; 12: 973 974.

62. Jousela I. Endotracheal tube versus face mask with and without continuous positive airways pressure (CPAP). Acta Anaesthesiol Scand 1992; 38: 382-385.

63. Pinilla J, Oleniuk F, Rebeyka I, Wilkinson A, Tanna $\mathrm{N}$, Bharadwaj B. Use of a nasal continuous positive pressure mask in the treatment of postoperative atelectasis in aortocoronary bypass surgery. Crit Care Med 1990; 18: 836-840.

64. Duncan S, Negrin R, Mihm F, Guilleminault C, Raffin T. Nasal continuous positive airway pressure in atelectasis. Chest 1987; 92: 621-624.

65. Miller R, Semple S. Continuous positive pressure ventilation for respiratory failure associated with
Pneumocystis carinii pneumonia. Respir Med 1991; 85: $133-138$.

66. Smith R, Kirby R, Gooding J, Civetta J. Continuous positive airway pressure (CPAP) by face mask. Crit Care Med 1980; 8: 483-485.

67. Suter P, Kobel N. Treatment of acute pulmonary failure by CPAP via face mask: When can intubation be avoided?. Klin Wochenscher 1981; 59: 613-616.

68. Branson R, Hurst J, DeHaven C. Mask CPAP: State of the art. Respiratory Care 1985; 30: 846-857.

69. Rasanen J, Vaisanen I, Hikkila J, Nikki P. Acute myocardial infarction complicated by left ventricular dysfunction and respiratory failure: the effects of continuous airway pressure. Chest 1985; 87: 158-162.

70. Brett A, Sinclair D. Use of continuous positive pressure in the management of community aquired pneumonia. Thorax 1993; 48: 1280-1281.

71. Gherini S, Peters R, Virgilio R. Mechanical work of the lungs and work of breathing with positive end expiratory pressure and continuous positive airway pressure. Chest 1979; 76: 251-256.

72. Ricksten S, Bengtsson A, Soderberg C, Thorolen M, Kvist $\mathrm{H}$. Effects of periodic positive airway pressure by mask on postoperative pulmonary function. Chest 1986; 89: 774-781.

73. Falk M, Kelstrup M, Andersedn J, Falk P, Stovring S. Improving the ketchup bottle method with positive expiratory pressure, PEP, in cystic fibrosis. Eur $J$ Respir Dis 1984; 65: 423-432.

74. Keilty S, Bott J. Continuous positive airways pressure. Physiotherapy 1992; 78: 90-92.

75. Ulyatt D, Judson J, Trubuhovich R, Galler L. Cerebral arterial air embolism associated with coughing on a continuous positive airway pressure circuit. Crit Care Med 1991; 19: 985-987.

76. Nishino T, Sugimori K, Hiraga K. Nasal constant positive airway pressure inhibits the swallowing reflex. Am Rev Respir Dis 1989; 140: 1290-1293.

77. Harrison D, Breen D, Harris N, Gerrish S. The performance of two intensive care humidifiers at high gas flows. Anaesthesia 1993; 48: 902-905.

78. Equipment. In: Simonds A, ed. Non-invasive respiratory support. London: Chapman and Hall, 1996; $16-37$.

79. Ellis E, Bye P, Bruderer. Treatment of respiratory failure during sleep in patients with neuromuscular disease. Am Rev Respir Dis 1987; 135: 148-152.

80. Piper A, Wilson G. Nocturnal nasal ventilatory support in the management of daytime hypercapnic respiratory failure. Aust J Physiotherapy 1996; 42: 17-29.

81. Carroll N, Branthwaite M. Control of nocturnal ventilation by nasal intermittent positive pressure ventilation. Thorax 1988; 43: 349-353.

82. Simonds A, Elliott M. Non-invasive ventilation in acute respiratory failure. In: Simonds A, ed. Noninvasive respiratory support. London, Chapman and Hall, 1996: 38-43.

83. Bott J, Carroll M, Conway J, et al. The effect of nasal intermittent positive pressure ventilation on acute exacerbations of chronic obstructive pulmonary disease (COPD). Am Rev Respir Dis 1991; 143: A472. 